\title{
O Carnaval do Mindelo, Cabo Verde: reflexões sobre a festa e a cidade
}

\author{
El Carnaval de Mindelo, Cabo Verde: reflexiones sobre la fiesta y la ciudad
}

The Carnival of Mindelo, Cape Verde: reflections on the festival and the city

\author{
Juliana Braz Diasi
}

Palavras chave:

Carnaval

Cidade

Escalas

Mindelo

Cabo Verde
Resumo:

Este artigo traz algumas reflexões sobre a relação entre o carnaval e a Cidade do Mindelo, na Ilha de São Vicente (Cabo Verde). Tal relação desenrola-se em um processo de influências mútuas, onde um age na constituição do outro, de modo dinâmico. Desenvolvo, especialmente, três pontos. Primeiro, numa perspectiva histórica, demonstro como o carnaval deve ser compreendido na sua vinculação à singularidade da formação social na Ilha de São Vicente. Em segundo lugar, trato das formas como o carnaval tem desafiado os limites internos à cidade, marcada pela coincidência de fronteiras entre bairros e estratos sociais. Por fim, abordo a questão da escala, apresentando o dilema vivido pelos habitantes de São Vicente, entre a pequenez da Ilha e o crescimento da sua festa maior, o carnaval. 


\section{Resumen:}

En este artículo se reflexiona sobre la relación entre el carnaval y la Ciudad de Mindelo, en la Isla de San Vicente (Cabo Verde). Esta relación se desarrolla en un proceso de influencias mutuas, donde uno actúa en la constitución del otro, dinámicamente. Discuto, en especial, tres puntos. En primer lugar, en un enfoque histórico, trato de mostrar cómo el carnaval debe entenderse en su relación con la singularidad de la formación social en la Isla de San Vicente. En segundo lugar, presento las formas en que el carnaval ha desafiado los límites internos a la ciudad, marcada por la coincidencia de los límites entre los barrios y estratos sociales. Por último, se aborda el tema de la escala, mostrando el dilema del pueblo de San Vicente, entre la pequeñez de la Isla y el crecimiento de su fiesta más grande, el carnaval.

\section{Palabras clave:}

Carnaval

Ciudad

Escalas

Mindelo

Cabo Verde

\section{Keywords:}

\section{Carnival}

City

Scales

Mindelo

Cape Verde

\section{Abstract:}

This article is a discussion on the relationship between the carnival and the City of Mindelo, in São Vicente Island (Cape Verde). This relationship unfolds in a process of mutual influences where one acts in the constitution of another, dynamically. The discussion aims at three points, in particular. First, with a historical perspective, I demonstrate how carnival should be understood in its relation to the uniqueness of the social formation of São Vicente Island. Second, I presenthow carnival has challenged the internal limits of the city, usually marked by the coincidence of boundaries between neighborhoods and social strata. Finally, I address the issue of scale, focusing on the dilemma experienced by the people of São Vicente, caught between the smallness of the Island and the growth of its biggest party, the carnival. 


\section{O Carnaval do Mindelo, Cabo Verde: reflexões sobre a festa e a cidade}

\section{Introdução}

Naquele 11 de fevereiro de 2015, uma quarta-feira que antecedia ao carnaval, estava em festa o Aeroporto InternacionalCesária Évora, na Ilha de São Vicente, em Cabo Verde. Era chegada de voo vindo de Amsterdã, trazendo gente ansiosa para se juntar aos festejos pelas ruas da Cidade do Mindelo. Muitos eram turistas, avisados de que aqueles seriam dias ideais para experimentar a musicalidade e a animação que fazem conhecida a pequena ilha atlântica. Outros tantos eram cabo-verdianos emigrados, filhos da terra que um dia deixaram o país natal em busca de uma vida melhor, mas que não deixam escapar a oportunidade de voltar, ainda que só por uns dias, e reviver o aconchego e a alegria de São Vicente.

A recepção dos recém-chegados foi à altura de suas expectativas. Logo à frente do aeroporto, deparavam-se com uma cena impactante: passistas, rainhas e uma porta-bandeira, em trajes coloridos, dançavam sob sol escaldante ao somproduzido pelos integrantes da bateria.Poderiam ser confundidos com uma escola de samba brasileira, não fosse pela paisagem ao redor. As características rochas nuas da IIha, castigadas pelo clima árido, serviam como moldura para uma estátua de Cesária Évora, a mais renomada filha da terra, que parecia olhar serena para a passista em movimento.

O carnaval de São Vicente tem sido pensado, por especialistas e gente comum, através desse prisma comparativo. O Brasil é sempre uma referência im- portante a balizar as reflexões sobre os festejos que animam as ruas da pequena ilha. Mas se o olhar para o outro lado do Atlântico não pode ser evitado, tampouco deve ofuscar o que Cabo Verde tem de próprio. Neste artigo, direciono a atenção para o carnaval de São Vicente em sua relação com a cidade, a ocupação dos espaços urbanos e a questão da escala. Busco revisitar um tema abordado por vários outros autores que se dedicaram ao estudo dos festejos de carnaval, sobretudo no Rio de Janeiro, atenta agora às singularidades da experiência carnavalesca pelas ruas do Mindelo.

Venho desenvolvendo pesquisas de caráter etnográfico sobre a cultura popular em Cabo Verde há mais de 15 anos. Minha atenção tem se voltado em especial para o gênero musical conhecido como "morna", um dos principais símbolos da identidade nacional cabo-verdiana (DIAS, 2004; 2008; 2010; 2011a; 2011b;2012a; 2012b; 2012c; 2014). A importância da música em Cabo Verde é revelada nas formas de sociabilidade locais e na maneira como os cabo-verdianos se pensam enquanto uma totalidade original. Sua relevância extrapola ainda a dimensão simbólica e ganha peso em projetos voltados para o desenvolvimento do país, no âmbito das "economias criativas" (FURTADO, 2014).

Apenas mais recentemente (nos últimos dois anos), comecei a incluir,entre as formas de cultura popular por mim analisadas,o carnaval." Seu impacto é igualmente notável nos processos de construção de identidade e nos projetos que buscam inserir a cultura popular no universo do turismo, a fim de torná-la cada vez mais atrativa ao visitante e economicamente rentável para a população local. Diferente da morna, que mobiliza os cabo-verdianos em nível nacional, o carnaval está relacionado mais diretamente à Ilha de São 
Vicente, uma das dez ilhas que compõem o arquipélago. Já existem atualmente alguns trabalhos voltados para a análise desse festejo, a exemplo da obra de Moacyr Rodrigues (2011), alguns artigos (SANSONE, 2012; VIEIRA FILHO, 2015) e outras investigações em andamento."I Considero, contudo, que o carnaval de São Vicente é ainda um fenômeno pouco explorado em termos antropológicos, podendo render discussões interessantes - tanto em sua singularidade, quanto nos aspectos que o conectam a festejos semelhantes no Brasil e em outras partes do mundo.

O que desenvolvo neste artigo são algumas reflexões iniciais sobre a relação do carnaval com a cidade, no contexto cabo-verdiano. Como afirmam Cavalcanti e Gonçalves (2009, p. 10), "[f]esta pública e urbana por excelência, o carnaval conclama os cidadãos a reivindicarem territórios para a folia - rua, avenida, passarela, pista, quadra, terreiro, praça, salão, palco, terraço, onde quer que se possa acender sua faísca". Essa relação entre a festa e a cidade desenrola-se em um processo de influências mútuas, onde uma age na constituição da outra, de modo dinâmico. Neste trabaIho, aponto para três desdobramentos da relação entre o carnaval e a Cidade do Mindelo. Primeiro, num plano histórico, demonstro como o carnaval deve ser compreendido na sua vinculação à singularidade da formação social na Ilha de São Vicente. Em segundo lugar, trato brevemente das formas como o carnaval tem desafiado os limites internos à cidade, que, no tempo comum, está marcada pela coincidência de fronteiras entre bairros e estratos sociais. Por fim, abordo a questão da escala, apresentando o dilema vivido pelos mindelenses, entre a pequenez da Ilha e o crescimento da sua festa maior, o carnaval.

\section{A cidade, o porto e o florescer da cultura popular}

São Vicente foi, das ilhas de Cabo Verde, a última a ser habitada. Se a carência de água impedia o uso daquelas terras vulcânicas para a agricultura e a criação de gado, frustrando os que ali tentavam viver, a existência de uma baía perfeita, quase desenhada à mão, trouxe à ilha sua possibilidade de desenvolvimento. Ao redor da baía, transformada em porto, nasceu o povoado que viria a constituir a Cidade do Mindelo, único aglomerado urbano da Ilha de São Vicente, onde se concentra a maior parte da população da Ilha, que alcançamenos de 80 mil habitantes, segundo dados do censo de 2010 (Instituto Nacional de Estatísticas de Cabo Verde, 2016).

Foi em meados do século XIX, em um período de intensos fluxos comerciais e migratórios no espaço atlântico, que a llha recebeu atenção especial. Navios a vapor cruzavam o oceano e necessitavam realizar escalas para reabastecimento de combustível. Nesse quadro, a localização de Cabo Verde como último ponto de parada possível na travessia atlântica revelou-se ideal para a criação de estações carvoeiras - e a baía segura, de águas profundas, que recorta o litoral de São Vicente foi então preparada para a construção do Porto Grande:

Junto ao porto, rapidamente cresceu a cidade. As estações carvoeiras empregavam grande quantidade de pessoas no trabalho de descarga, armazenamento e recarregamento do carvão. Mas o porto demandava mais. Demandava pessoal para trabalhar na venda de água e alimentos (também essenciais no reabastecimento dos navios), além de certa infraestrutura para receber os passageiros em trânsito. Fez-se igualmente necessária a 
instalação de mecanismos administrativos e políticos do Estado português (DIAS, 2004, p. 97).

A Cidade do Mindelo cresceu rapidamente, a partir dos deslocamentos populacionais com origem nas ilhas vizinhas (Santo Antão e São Nicolau).Mindelo ganhou fama no arquipélago pela vida agitada, o fluxo de gente, novidades vindas de fora. No ano de 1888, quando - Porto Grande vivia sua melhor fase, desembarcaram no Mindelo 169.440 passageiros em trânsito (CORREIA E SILVA, 2000, p. 131). Eram pessoas de nacionalidades diversas que traziam vida e transformavam o cotidiano.

O contexto portuário foi especialmente significativo para imprimir na cidade que nascia seu caráter cosmopolita. $E$ tal abertura ao mundo teve consequência direta na criação de novas formas de lazer e de sociabilidade. A cultura popular em São Vicenteé fruto desse trânsito de pessoas, ideias, valores e coisas. Nos esportes, por exemplo, é notável a influência inglesa. A população de São Vicente gaba-se por serem filhos da única ilha de Cabo Verde onde floresceram práticas como o golfe e o críquete. No campo musical, outros movimentos mostraram-se relevantes. Atribui-se aos marinheiros vindos do Brasil a influência no gosto e na prática musical cabo-verdiana. O país-irmão, do outro lado do Atlântico, é referência importante. Nos discursos que se ouve em Cabo Verde, menciona-se sempre que a contribuição de São Vicente à configuração atual da morna, o gênero musical nacional, está associada a apropriações de modos brasileiros de tocar e falar (DIAS, 2011a). Igualmente, relacionam-se aos fluxos interatlânticos as cores do carnaval de São Vicente, com traços brasileiros reelaborados e ressignificados pelos ilhéus.

O Porto Grande teve seu auge em fins do século XIX, mas mesmo nas déca- das seguintes, com sua gradual decadência, ainda era fundamental porta de entrada de práticas estrangeiras, rapidamente incorporadas no modo de ser dos mindelenses. No Brasil, na cidade do Rio de Janeiro, as escolas de samba começaram a surgir na década de 1920 (CAVALCANTI, 1995 , p. 22).Segundo a cronologia apresentada por Cavalcanti (ibid., p. 23), com base na crônica carnavalesca, a primeira escola de samba carioca ("Deixa Eu Falar", do bairro do Estácio) teria sido criada no final daquela década. Em seguida, seria formada a Mangueira e, em 1932, a escola "Vai Como Pode", mais tarde conhecida como Portela. Ao que tudo indica, o surgimento do carnaval no Mindelo, no formato de grupos organizados, é praticamente contemporâneo ao fenômeno no Brasil:

Grupos como Florianos datam de 1920, com orquestra própria, com a sua sede, fazendo os seus famosos bailes, constituído, principalmente, de pequenos funcionários públicos; outros já aparecem, como Nacional (1939), onde já surge o primeiro andor, representando o avião Lusitânia, que levou Gago Coutinho e Sacadura Cabral ao Brasil em 1922, que escalou o Porto Grande; Sousa Cruz (1936) da Ribeira Bote, Grupo Monte dos Amores (1936) do Monte Sossego (RODRIGUES, 2011, p. 57).

Noto, com isso, que não se trata de uma influência tardia, com Cabo Verde apropriando-se de um já estabelecido fenômeno carioca. Dos dois lados do Atlântico, o carnaval foi sendo criado como produto de configurações sociais específicas, mas conectadas por fluxos de várias ordens, cruzando o oceano.

Ainda hoje a semelhança entre o carnaval carioca e o mindelense provoca calorosas discussões. Como uma pesquisadora brasileira em terras cabo-verdianas, fui recorrentemente questio- 
nada a respeito de minha opinião sobre o assunto. De maneira geral, procuravam pelo meu aval, a fim de fortalecer o argumento de que o carnaval do Mindelo é, de fato, como o do Brasil - guardadas apenas as diferenças nas suas proporções (tema de que tratarei adiante). Em termos de uma pesquisa de cunho antropológico, penso que o mais relevante seja, por um lado, observar a importância dessa conexão com o Brasil no modo como a população de São Vicente constrói sua singularidade frente às demais ilhas (DIAS, 2004; 2011a); por outro lado, atentar-se aos fluxos históricos e não-hegemônicos (RIBEIRO, 2010), feito pelas mãos de gente simples, sobretudo marinheiros, protagonistas na construção de um mundo atlântico.

Para melhor compreensão do carnaval do Mindelo, o cosmopolitismo que até hoje caracteriza São Vicente não é o único aspecto da formação social da Ilha a ser ressaltado.Mesmo a organização espacialda cidade, com traços próprios do mundo urbano, era uma característica que, no século XIX, surpreendia os cabo-verdianos até então acostumados a uma existência baseada na agricultura e que se adequava bem às manifestações de cultura popular nascentes.

Intimamente associada ao contexto portuário, a Cidade do Mindelo reuniu, ainda muito cedo, as vantagens e as desvantagens das aglomerações urbanas modernas. A população da cidade era formada, em larga medida, por um proletariado portuário. Os camponeses pobres das ilhas vizinhas que chegavam para trabalhar no Porto Grande precisavam enfrentar um processo de mudança profunda, passando a integrar uma nova classe social. Como argumenta Correia e Silva (2000, p. 122-124), a transformação desse grupo em operariado urbano deu-se por meio de uma verdadeira socialização empreendida pelos ingleses, proprietários das companhias carvoeiras sediadas no Mindelo. Os ingleses empenharam-se na construção de bairros operários em São Vicente, nos moldes das concentrações urbanas da Inglaterra industrializada, alterando o cotidiano da população e suas relações com o tempo e o espaço.

[...] o crescente proletariado sanvicentino desenvolvia progressivamente um modo de ser peculiar, nas práticas e valores que compartilhavam e nas formas culturais a que davam origem. Foi nesse meio, entre essas pessoas, que ganhou projeção a morna, experienciada em situações diretamente relacionadas ao cotidiano da população de trabalhadores. Ao fim de um longo dia de trabalho, era ao violão, ao som das mornas, que muitos homens do porto encontravam seu merecido descanso - tocando seu instrumento à soleira das portas, no movimento das tabernas ou mesmo na diversão dos bailes a pau-e-corda (DIAS, 2004, p. 101).

Foi também nesse contexto portuário que surgiram as condições de desenvolvimento das práticas carnavalescas. O carnaval do Mindelo, como fenômeno urbano, ainda hoje reflete as desigualdades que caracterizam a cidade. Os diferentes bairros, associados a diferentes estratos sociais, revelam formas diversas de brincar o carnaval. E a festa apresenta-se como objeto privilegiado para uma análise dos vínculos e das rupturas que marcam esse espaço citadino heterogêneo.

\section{E o carnaval desce à Morada...}

No tratamento que dá ao carnaval carioca, Maria Laura Cavalcanti tem argumentado recorrentemente sobre a relação entre os desfiles das escolas de 
samba e a cidade do Rio de Janeiro: "[s] ua capacidade de articulação social, de estabelecer mediações socioculturais entre diferentes bairros e regiões da cidade, entre morro e asfalto, foi, e é ainda hoje, de fato, ímpar" (CAVALCANTI, 2009 , p. 9).Se o carnaval carioca tem início, ainda nos anos 1920, de forma estratificada - "a cada camada social, um grupo carnavalesco, uma forma particular de brincar o carnaval" (CAVALCANTI, 1995, p. 23) -, as escolas de samba teriam demonstrado sua incrível capacidade de mediação, desorganizando as antigas distinções. $O$ foco da autora no caráter mediador das relações sociais que se desenvolvem a partir do carnaval carioca apresenta continuidade com a clássica análise de DaMatta (1997) sobre o fenômeno: um ritual capaz de elaborar mediações e encontros, inventando um momento igualitário.

Tal dimensão do carnaval pode também ser investigada no caso mindelense, resguardando suas especificidades. Na vida cotidiana, a Cidade do Mindelo está espacialmente organizada em bairros, cujas fronteiras coincidem com aquelas que separam diferentes camadas da sociedade. No centro da cidade, está a região conhecida como Morada. Nela reside a elite do Mindelo - intelectuais, comerciantes, administradores. Nas zonas periféricas, de maneira geral, estão os bairros que, "como no passado, são ainda hoje verdadeiros dormitórios de homens que tanto trabalhavam no mar" (RODRIGUES, 2011, p. 39) e, em terra, nas ocupações mais precárias, como a construção civil e serviços domésticos. $E$ é nos bairros - Lombo, Ribeira Bote, Monte Craca, Fonte Felipe, Bela Vista, Monte Sossego, entre outros - que vive grande parte dos artistas envolvidos no carnaval (ibid., p. 47). A distribuição da festa por esses espaços e estratos sociais é complexa e está associada a distintos modos de brincar o carnaval em São Vicente.
Aqui, limito-me a lançar algumas informações e ideias, a serem desenvolvidas em outro momento.

De forma um pouco simplista, é possível dividir o carnaval mindelense em três tipos de evento: os Bailes, os Mandingas e os desfiles dos Grupos de Carnaval. Os Bailes acontecem sobretudo no sábado de carnaval. São eventos fechados, organizados em hotéis, destinados a elite local. Paga-se caro pelo ingresso, que dá direito a música ao vivo, jantar e concurso de fantasias, com prêmios cobiçados.

Já os Mandingas remetem às camadas mais pobres da população mindelense. Trata-se de uma prática relativamente nova, que vem ganhando destaque ano a ano. São grupos que partem dos bairros periféricos, desfilando pela cidade e agregando multidões, adornados de maneira muito característica. Os corpos mestiços de jovens cabo-verdianos são pintados com uma mistura de óleo de cozinha e o pó preto extraído das pilhas. A pele, que ganha assim um tom negro, muito escuro, é combinada ao vestuário, composto por saias de saco, plástico ou sisal, além de outros acessórios, como colares e lanças, objetivando alcançar o aspecto de um "africano selvagem", imaginado. Há gritos de guerra, danças e músicas próprias dos grupos de Mandingas. Desfilam pelas ruas da cidade nas tardes de domingo, começando no primeiro domingo de janeiro e seguindo até aquele que antecede a terça-feira de carnaval. No domingo imediatamente após o carnaval, realizam ainda o evento conhecido como o Enterro dos Mandingas. Trata-se de uma prática complexa, que inspira reflexões de várias ordens. Opto aqui por apenas sinalizar a presença muito importante dos Mandingas, concentrando-me, mais detidamente, nos Grupos de Carnaval. 
Estes últimos têm longa história. São a feição do carnaval mindelense que mais se aproxima da festa carioca. Trata-se de grupos organizados, que desfilam pelas ruas da Morada na terça-feira de carnaval - o local e o dia mais nobres do festejo. Semelhantes às escolas de samba do Rio de Janeiro, os principais Grupos de Carnaval estão vinculados ao local onde estão sediados, acionando pertenças:Cruzeiros do Norte (bairro Cruz João Évora), Monte Sossego (bairro de mesmo nome) e Vindos do Oriente (Morada). Depois de ensaios diários que acontecem ao longo de um período de mais ou menos um mês, descem todos à Morada, compostos por andores e diversas alas, movimentando-se em passos coreografados, ao som da bateria, cujo ritmo difere sensivelmente dos sambas-enredos brasileiros. Os grupos oficiais participam de uma competição, com critérios rígidos e jurados anônimos, que premiam a melhor música, o melhor carro alegórico, a rainha de bateria, o mestre-sala, a porta-bandeira, $1^{a}$ e $2^{a}$ damas, rei e rainha, além do melhor grupo no geral.

Pode-se dizer que, em certo sentido, o desfile dos Grupos de Carnaval tem um caráter igualitário, permitindo que coletivos de pertenças diversas, relacionados a bairros e estratos sociais diferentes, possam se reunir todos na região mais prestigiosa da cidade, em um concurso que os nivela. Como já apontava DaMatta,

[...] a ideia de competição (isto é, concurso entre iguais) é algo banido do universo hierarquizado. Nele, ninguém deve subir por meio de provas, o que colocaria o desempenho adiante de outros critérios muito mais importantes, como o nascimento, a residência, a cor da pele etc. (os critérios substantivos). Mas no carnaval tudo é feito por meio de concursos, de modo que o idioma da sociedade se transforma. De uma linguagem hierarquizada, passamos a uma linguagem competitiva e igualitária, já que se procura promover uma oportunidade para todos (DAMATTA, 1997, p. 148).

Porém, assim como no universo brasileiro, também em Cabo Verde o caráter igualitário do carnaval não reina soberano. Saídas são encontradas para manter atuantes no carnaval as diferenças que imperam na vida cotidiana. Em São Vicente, se a terça-feira gorda é o dia do desfile competitivo, a segunda-feira de carnaval é reservada ao desfile de um grupo especial, o Samba Tropical. Este não é aberto a todos (RODRIGUES, 2011, p. 61), nem compete com ninguém. Considerado mais luxuoso e refinado, atrai especialmente a elite local, além de gente de fora da llha e da diáspora, em condições de pagar pelos trajes de preços elevados.

Em "Um carnaval à francesa: a construção da folia na cidade de Nice", Ferreira (2009) realiza interessante comparação entre a organização do espaço urbano e os estilos de carnaval em Nice e no Rio de Janeiro. O autor argumenta que a metrópole brasileira não teve seu crescimento aliado à incorporação de novos espaços, e sim à sobreposição de diferentes "cidades", com aproximação física de habitantes de diferentes origens sociais. Tal disposição espacial teria favorecido uma situação em que "diferentes jeitos de brincar carnaval dialogassem uns com os outros, influenciando-se mutuamente e dando espaço para o surgimento das mais variadas formas de diversão" (FERREIRA, 2009, p. 32). Em contraste, a forma de desenvolvimento urbano da cidade de Nice, com a manutenção da Cidade Velha e a construção da parte moderna na outra margem do rio Paillon, teria levado a existência de diferentes carnavais, com espaços pró- 
prios e relativo isolamento entre si. A segregação seria a marca do organizado carnaval niciense.

Tal análise mostra-se inspiradora para um estudo do carnaval mindelense. Aqui, com planos de desenvolvimentos futuros, limito-me a sugerir que a festa, em São Vicente, combina episódios de encontros(com misturas e dissoluçãotemporária das fronteiras internas à cidade) a situações de conflitos e distanciamentos. Uma análise mais detida sobre essa ambivalência necessita combinar os modos de organização espacial da cidade às características próprias dessa sociedade crioula, fruto do colonialismo português, onde historicamente os diversos estratos sociais estiveram sempre em contato intenso. Trata-se de uma sociedade estratificada mas não segregada, e que tem nas manifestações

\section{Carnaval de São Vicente (Manuel D'Novas)}

J'a'mconchia São Vicente Na sê ligria na sê sabura Ma'mcapudfazê ideia S'na carnaval era mas sab

São Vicente é um brasilin Cheidiligriacheidi cor Ness três dia di loucura Ca ten guerra ê carnaval Nessmorabezasen igual [...]

Chamo atenção especial para o verso "São Vicente é um brasilzinho" (no original em crioulo "brasilin"). Esse verso revela, de forma condensada, não só a proximidade entre Brasil e Cabo Verde, mas também o contraste entre suas dimensões. A Ilha de São Vicenteé, nas palavras dos próprios cabo-verdianos, "um grãozinho de terra". A Cidade do Mindelo conta com aproximadamente de cultura popular uma de suas grandes forças unificadoras. IV

\section{Um carnaval no diminutivo}

Neste trabalho em que levanto uma série de questões sobre o carnaval do Mindelo visando investigações futuras, abordo, por fim, o problema da escala e sua influência no festejo - em particular, no que toca ao desfile dos grupos competitivos. Para tanto, é necessário retomar a relação do carnaval mindelense com o Brasil, que frequentemente traz à tona a reflexão da população de São Vicente sobre as dimensões de sua festa.

A relação entre São Vicente e o Brasil ficou eternizada nos versos do compositor Manuel D'Novas, cantados por Cesária Évora:

\section{Carnaval de São Vicente \\ (Manuel D’Novas)}

Eu já conhecia São Vicente

$\mathrm{Na}$ sua alegria e nos seus prazeres

Mas eu não podia ter ideia

De que no carnaval era mais gostoso

São Vicente é um brasilzinho

Cheio de alegria e cheio de cor

Nesses três dias de loucura

Não há brigas, é carnaval

Nessa cordialidade sem igual [...]

70.000 habitantes, enquanto o Rio de Janeiro abriga mais de 6 milhões de pessoas - e,se levarmos em conta toda a região metropolitana, chegamos a mais de 12 milhões de habitantes, na terceira maior conurbação da América do Sul.

Apesar de a população do Mindelo nutrir significativa autoconsciência sobre seu tamanho reduzido, começa 
a enfrentar recentemente a necessidade de reavaliar as dimensões do seu carnaval. As ruas da Morada que tradicionalmente foram palco para a festa começam a se mostrar pequenas para Grupos de Carnaval cada vez maiores e um público crescente. Retomo aqui a situação descrita na abertura deste artigo. Além da população local, que participa em massa da festa, o carnaval atrai turistas nacionais e estrangeiros, resultado, entre outros fatores, do forte investimento do governo na espetacularização do evento, movimentando a economia frágil da Ilha de São Vicente. ${ }^{V}$ Notória também é a grande quantidade de migrantes cabo-verdianos que, depois de meses distantes da terra natal, voltam para desfrutar da alegria carnavalesca em São Vicente, trazendo movimento, cores e ruídos à cidade. $\mathrm{E}$ a população local desenvolve sentimentos ambíguos com relação a isso.Trata-sedos dilemas de uma festa popular que cresce, revelando sua vivacidade, ao mesmo tempo em que encontra dificuldades de se expandir mantendo suas características originais.

Uma das iniciativas tomadas pelo governo local a fim de organizar o afluxo de pessoas durante o carnaval de São Vicente foi a instalação de cordas ao longo das principais avenidas da Morada, impedindo que o público atravesse os espaços a serem preenchidos pelos Grupos de Carnaval durante o desfile competitivo. A medida é polêmica, gerando a insatisfação de grande parte da população, que se acumula nas calçadas tentando se acomodar minimamente, como podemos observar na fig. 1.

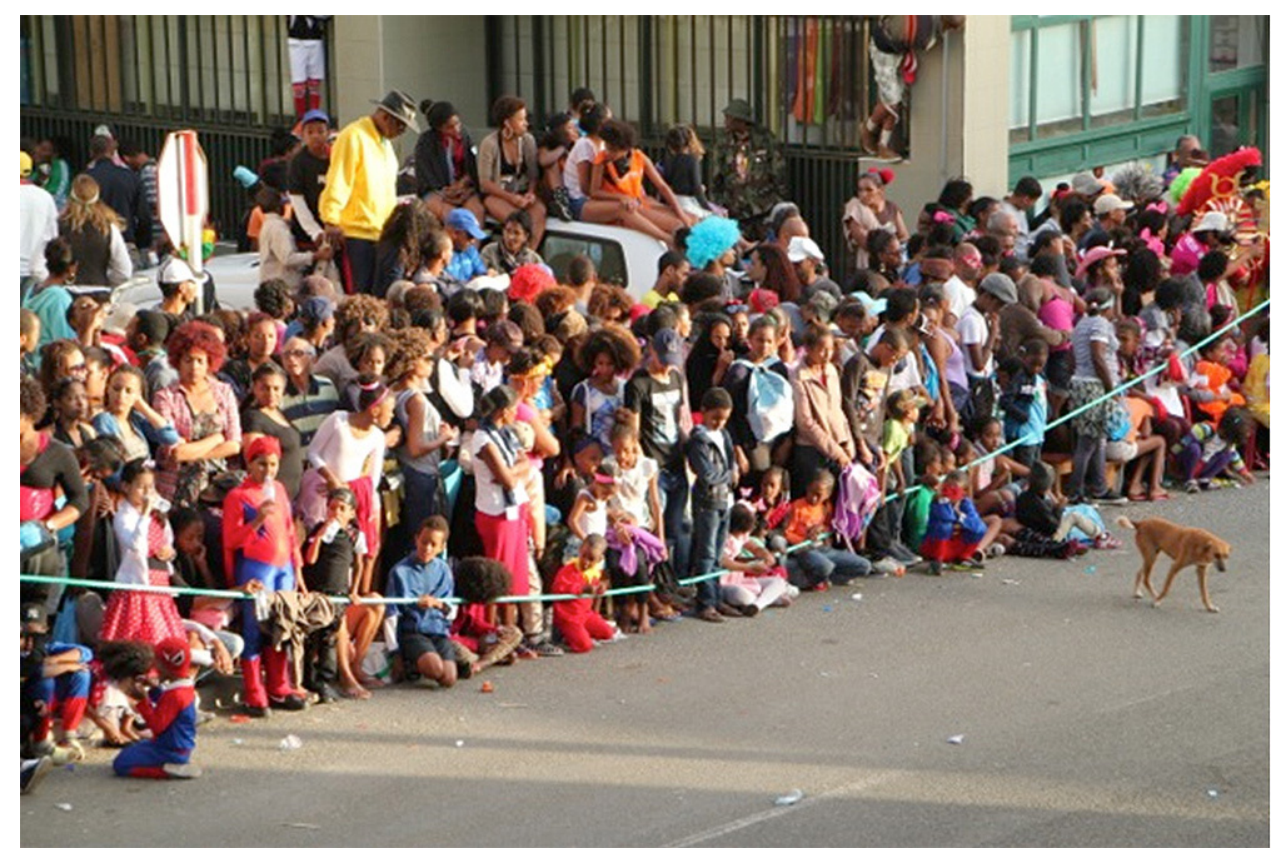

Fig. 1: A organização das ruas para o desfile de carnaval (Mindelo, 2015). Foto da autora

Por causa do grande afluxo de pessoas, outra medida tomada pelos administradores diz respeito à segurança. A polícia e o exército são acionados durante todo o evento com o objetivo de evitar incidentes violentos e de manter o público no local a ele reservado, organizando o uso do espaço urbano durante a 
festividade. Os habitantes têm, portanto, o uso da cidade controlado por medidas que estabelecem limites na circulação urbana. E o clima de festa é alterado pela presença ostensiva da força do Estado.

Outro tema de discussão frequente entre a população do Mindelo no que tange ao carnaval é o fato de que os grupos oficiais, que integram a competição, têm crescido consideravelmente em número de participantes. Para se ter ideia, - Grupo Carnavalesco Monte Sossego levou em torno de 3.000 integrantes às ruas durante o Carnaval 2015 - quase $5 \%$ da população da llha. Trata-se de uma marca histórica que se revela, por exemplo, na maior ala de baianas presenciada no festejo.

A dimensão dos carros alegóricos tem se mostrado outro problema recorrente ao longo do percurso por entre ruas e avenidas da Morada, com muitas árvores e fios de eletricidade.
Muitas vezes provocam o atraso dos grupos de carnaval e a consequente perda de pontos na criteriosa avaliação dos jurados. Os carros alegóricos - localmente "andores" - transformam o uso das pequenas ruas e principais avenidas do Mindelo, num impacto visual de volume e cor.

Trava-se uma verdadeira luta pela ocupação de espaços da cidade - não apenas pelos membros dos grupos oficiais, mas também pelo numeroso público, personagem ativo da festa, que ocupa janelas, varandas e terraços em busca de melhor visão do evento. Como podemos notar na fig. 2, constrói-se um quadro impactante. Por um lado, podem ser observados os usos criativos dos espaços urbanos, na vitalidade dos formas de cultura popular. Por outro, transparecem os limites físicos desses mesmos espaços para comportar um número crescente de participantes do maior evento da cidade.

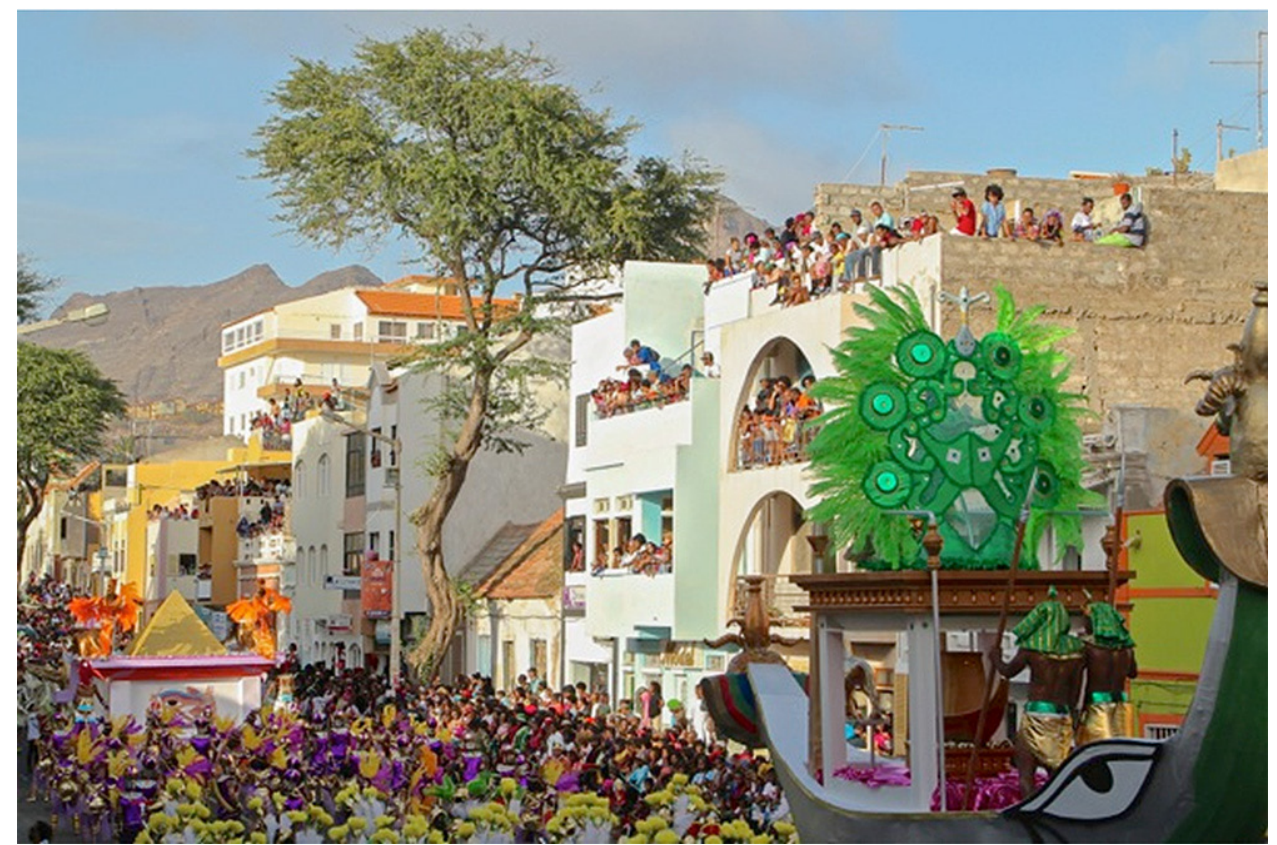

Fig. 2: Desfile do grupo campeão, Vindos do Oriente (Mindelo, 2015). Foto da autora 
Diante de tal quadro, uma dúvida preenche as discussões da população mindelense, do cidadão comum aos responsáveis pela elaboração de políticas públicas: a alternativa mais apropriada seria a construção de um sambódromo como já feito no Brasil? Seria esta a solução de um carnaval que, há tempos, tem como critério de excelência a festa carioca, com seu padrão "made in Brazil"? A pergunta continua gerando reflexões e poucas certezas diante das alterações que provocaria no estilo cabo-verdiano de brincar o carnaval.
A contenção do público nas calçadas, da maneira como já vem sendo realizada, tem sido alvo de muitas críticas. Em particular, ela é associada à diminuição do número de "grupos de animação", isto é, pequenos grupos que se reúnem de forma mais espontânea para exibir fantasias inusitadas e performances criativas e bem humoradas durante os intervalos dos desfiles dos Grupos de Carnaval oficiais, a exemplo do que se observa na fig. 3.

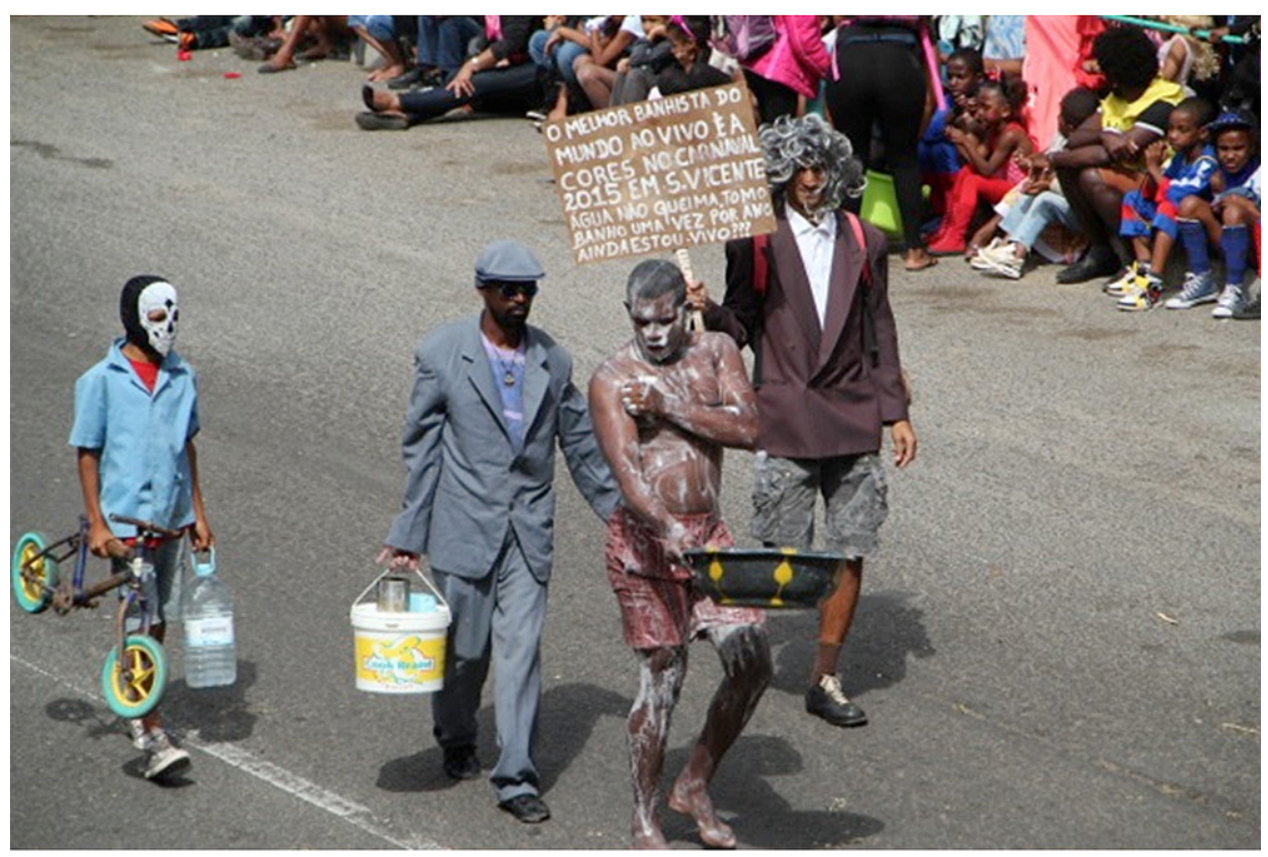

Fig. 3: "Grupo de animação" em desfile pela Morada (Mindelo, 2015). Foto da autora

Não são raros os discursos de cunho mais purista que veem nos "grupos de animação" o que de mais espontâneo e autêntico há no carnaval mindelense. São discursos que lamentam a diminuição dessas performances frente ao crescimento dos aspectos mais turísticos do carnaval do Mindelo - aqueles mais grandiosos, cheios de brilho e cor, que se assemelham ao carnaval carioca. As iniciativas do próprio governo são ambivalentes. Enquanto se considera a ins- talação de arquibancadas e a espetacularização do carnaval visando o turismo, foi tomada uma iniciativa na direção contrária em 2016, objetivando a preservação e o estímulo aos grupos "espontâneos", supostamente mais "autênticos". É o Prêmio Kakoy, resultado dos esforços do Centro Nacional de Artesanato e Design em parceria com a Câmara Municipal de São Vicente, que veio laurear a criatividade da população local que se apresenta nos "grupos de animação". 
O dilema do carnaval cabo-verdiano encontra paralelo em diversas manifestações da cultura popular, em contextos variados. No próprio carnaval carioca, não foi sem desafios que se criou a monumental Passarela do Samba, com 85.000 metros quadrados e lugares para uma plateia de 59.092 pessoas (CAVALCANTI, 1995, p. 29) - certamente, um elemento transformador da experiência de se brincar carnaval no Rio de Janeiro:

A construção de arquibancadas na Avenida Rio Branco, em 1962, com a venda de ingressos ao público, iniciou o irreversível processo de comercialização do desfile, e a procura, muitas vezes dramática, por parte das escolas de um lugar adequado para o seu carnaval. O sucesso dos desfiles fez com que, de ano a ano, as arquibancadas crescessem. [...] A construção da Passarela do Samba em 1984 coroou essa evolução, e representou o reconhecimento e a extraordinária ampliação do potencial econômico dos desfiles (CAVALCANTI, 1995, p. 26-28).

O interesse pelo caso cabo-verdiano no que toca aos dilemas da espetacularização do carnaval e sua inserção no universo das "economias criativas" está no momento inicial em que ainda se encontra, quando se torna possível analisar de perto as diversas dimensões desse processo, com suas particularidades locais. O significativo exemplo do gigantesco Brasil, país-irmão do outro lado do Atlântico, e a simultânea valorização da pequenez cabo-verdiana são parte fundamental do modo local de experienciar os dilemas da espetacularização da cultura popular.

Longe de buscar aqui uma resposta para tal dilema, procuro apenas indicar como esta é uma questão relevante a ser trabalhada pela antropologia. Aliás, todo este artigo configura-se, ao fim, como um conjunto de insights e sugestões para investigações futuras, revelando a riqueza do carnaval do Mindelo para se pensar a relação entre a festa e a cidade, nas suas múltiplas configurações.

\section{Bibliografia}

CAVALCANTI, Maria Laura Viveiros de Castro. Carnaval Carioca: dos bastidores ao desfile. Rio de Janeiro: Editora UFRJ/ MinC/Funarte, 1995.

CAVALCANTI, Maria Laura Viveiros de Castro. Prefácio. In: SANTOS, Nilton Silva dos. A arte do efêmero: carnavalescos e mediação cultural na cidade do Rio de Janeiro. Rio de Janeiro: Apicuri, 2009. p. 9-12.

CAVALCANTI, Maria Laura Viveiros de Castro; GONÇALVES, Renata de Sá. Apresentação. In: CAVALCANTI, Maria Laura Viveiros de Castro; GONÇALVES, Renata de Sá (orgs.). Carnaval em Múltiplos Planos. Rio de Janeiro: Aeroplano, 2009. p. 9-14.

CORREIA E SILVA, António Leão. Nos Tempos do Porto Grande do Mindelo. Praia: Centro Cultural Português, 2000.

DAMATTA, Roberto. Carnavais, malandros e heróis: para uma sociologia do dilema brasileiro. 6 . ed. Rio de Janeiro: Rocco, 1997.

DAUN E LORENA, Carmo. Ambivalências identitárias em Cabo Verde: da história à etnografia. Análise Social, n. 217, L (4º), p. 784-808, 2015.

DIAS, Juliana Braz. Cape Verde and Brazil: musical connections. Vibrant, vol. 8, n. 1, 2011a.

DIAS, Juliana Braz. Entre virtudes e vícios. Trans - Revista Transcultural de Música, vol. 15, 2011b.

DIAS, Juliana Braz. Música cabo-verdiana, música do mundo. In: DIAS, Juliana Braz; LOBO, Andréa de Souza (orgs.). África em Movimento. Brasília: ABA Publicações, 2012a. p. 85-102.

DIAS, Juliana Braz. Música e experiência na era da reprodução digital. Anuário Antropológico, vol. 39, n. 1, p. 219-240, 2014.

DIAS, Juliana Braz. Popular music in Cape Verde: resistance or conciliation? In: FALOLA, Toyin; 
FLEMING, Tyler (eds.). Music, Performance and African Identities. Nova York: Routledge, 2012b. p. 316-328.

DIAS, Juliana Braz. Registros fonográficos da música cabo-verdiana: mercadoria e patrimônio. In: SANSONE, Livio (org.). Memórias da África: patrimônios, museus e políticas das identidades. Salvador/ Brasília: EDUFBA/ ABA Publicações, 2012c. p. 41-65.

DIAS, Juliana Braz. Sentimentos vividos: experiências com a música cabo-verdiana. Música \& Cultura, vol. 5, 2010.

DIAS, Juliana Braz. Images of Emigration in Cape Verdean Music. In: BATALHA, Luís; CARLING, Jorgen (eds.). Transnational Archipelago: Pespectives on Cape Verdean Migration and Diaspora. Amsterdã: Amsterdam University Press, 2008. p. 173-187.

DIAS, Juliana Braz. Mornas e Coladeiras de Cabo Verde: versões musicais de uma nação. (Doutorado em Antropologia Social). Universidade de Brasília, 2004.

FERREIRA, Felipe. Um carnaval à francesa: a construção da folia na cidade de Nice. In: CAVALCANTI, Maria Laura Viveiros de Castro; GONÇALVES, Renata de Sá (orgs.). Carnaval em Múltiplos Planos. Rio de Janeiro: Aeroplano, 2009, p. 15-34.

FURTADO, Carmem Liliana Teixeira Barros. Múzikas e Ka Múzikas: a música nas economias criativas e na produção musical local em Cabo Verde. (Doutorado em Ciências Sociais). Universidade de Cabo Verde, 2014.

INSTITUTO NACIONAL DE ESTATÍSTICA DE CABO VERDE. IV ${ }^{\circ}$ Recenseamento Geral da População e Habitação - Censo 2010. Disponível em: http://www.ine.cv/censo/files/Resumo\%20indicadores\%20RGPH\%202010.pdf. Acesso em: 18 de maio de 2016.

RIBEIRO, Gustavo Lins. A Globalização Popular e o Sistema Mundial Não-hegemônico. Revista Brasileira de Ciências Sociais, vol. 25, n. 74, p. 21-38, 2010.

RODRIGUES, Moacyr. O Carnaval do Mindelo. Formas de reinvenção da festa e da sociedade - representações mentais e materiais da cultura mindelense. Lousa: Gráfica Manuel Barbosa \& Filhos, 2011.

SANSONE, Livio. Uso e Abuso do Afro do Brasil na África. In: BRAZ DIAS, Juliana; LOBO, Andréa de
Souza (orgs.). África em Movimento. Brasília: ABA Publicações, 2012, p. 151-172.

VIEIRA FILHO, Raphael Rodrigues. Fragmentos e reminiscências dos dois lados do Atlântico: os mandingas de Mindelo e os Cãos de Jacobina. Revista África(s), vol. 2, n. 3, p. 41-58, 2015.

\section{Recebido em 27/07/2016 Aprovado em 11/08/2016}

I Juliana Braz Dias. Doutora em Antropologia. Professora da Universidade de Brasília, Brasil. Contato: jbrazdias@hotmail.com

II Minha pesquisa sobre o carnaval em São Vicente foi realizada no âmbito do projeto "Transformações do mundo de circulação nas formas estabelecidas de sociabilidade", desenvolvido através de uma parceria entre a Universidade de Brasília e a Universidade de Cabo Verde, com financiamento do Programa Capes/AULP (Programa Internacional de Apoio à Pesquisa e ao Ensino por meio da Mobilidade Docente e Discente Internacional). O trabalho de campo teve lugar na Cidade do Mindelo, entre novembro de 2014 e fevereiro de 2015.

III No artigo "Ambivalências identitárias em Cabo Verde: da história à etnografia" (DAUN E LORENA, 2015), a autora faz menção ao seu projeto de doutorado, intitulado "História colonial e processos de construção identitária em Cabo Verde: um estudo sobre o carnaval do Mindelo", desenvolvido no Instituto de Ciências Sociais da Universidade de Lisboa.

IV A esse respeito, ver a análise desenvolvida em outra ocasião (AUTOR, 2004) sobre os chamados "bailes nacionais" em Cabo Verde, que no passado colonial reuniam, em um único evento, elite e povo, imersos em atos de música e sociabilidade. Longe de ser uma comprovação da "harmonia social do mundo luso-tropical", o fenômeno era apenas mais um exemplo, no universo colonial cabo-verdiano, da existência de certa acomodação às desigualdades de poder, com a convivência regular entre pessoas de diferentes estratos sociais.

V Em maio de 2016, o recentemente empossado Ministro da Cultura, Abraão Vicente, afirmou que não poupará esforços para garantir que o carnaval mindelense seja um "ex-líbris nacional e internacional", atraindo turistas e movimentando a economia da Ilha de São Vicente. Ver: http://carnaval.sapo.cv/carnavaldomindelo/ artigo/abraao_vicente_vamos_garantir_que_o_carnaval_do_mindelo_seja_um_ex_libris-47552qhr.html. 